ties (that is now the governors' job), and boards are particularly seeking non-executive directors with skills such as finance, business, and marketing. Some boards now meet in private, raising concerns over transparency. If the role of the governor is not clarified and strengthened, foundation trusts risk becoming less accountable to the public. ${ }^{7}$

One concern about the advent of foundation trusts was that they might threaten cooperation between healthcare organisations serving local communities, ${ }^{3}$ but the review has found no evidence of this. Current relations between organisations are usually determined strongly by past relations. Where trusts have worked well with local organisations previously, relations have remained good; where they were poor, they have worsened. In some cases foundation trusts have withdrawn from local planning meetings. Clinical relationships, however, have remained largely unchanged, with NHS consultants in foundation trusts still belonging to cross organisational clinical networks.

Foundation trusts have arrived at a time of other far reaching developments in NHS policy, such as a new payment system for hospitals and a new contract for consultants. These other factors have created a turbulent environment for the early foundation trusts. In a carefully worded criticism of the Department of Health's management of policy, the Healthcare Commission calls for better coordination of national policy and for the likely impact of new arrangements to be assessed before implementation.

\section{Something for everyone, but no clear message}

For those hoping to reach a clear judgment about the usefulness of foundation trusts, this week's report by the Healthcare Commission is bound to be something of a disappointment. The review offers something for both proponents and detractors of this policy. Foundation trusts have, not yet at least, declared wholesale independence from local partnerships in the NHS. Nor have they ushered in a two tier service. Most importantly, they do not seem to have offered any particular advantage to patients. A poor return, perhaps, for so much effort and expense.

Have foundation trusts been afforded the wrong freedoms, or insufficiently powerful ones? Or have they not yet reached maturity? With these questions in mind, the Healthcare Commission ends its report with a call for a further review in two years. In the meantime, however, the rumbling row over foundation trusts is likely to continue.

Richard Q Lewis fellow in health policy

King's Fund, London W1G 0AN

(R.lewis@kingsfund.org.uk)

Competing interests: RQL was an unpaid member of the Healthcare Commission's foundation trust review advisory panel and offered advice on the analysis and presentation of data.

1 Secretary of State for Health. The NHS improvement plan: putting people at the heart of public services. London: HMSO, 2004. (Cm 6268.) www.dh.gov.uk/assetRoot/04/08/45/22/04084522.pdf (accessed 1 Jul 2005).

2 Department of Health. A guide to foundation trusts. London: Department of Health, 2002. www.dh.gov.uk/assetRoot/04/02/99/90/04029990.pdf (accessed 1 Jul 2005).

3 Unison. Seven reasons why UNISON is opposed to Foundation Trusts. 2003. www.unison.org.uk/acrobat/B799.pdf (accessed 1 Jul 2005).

4 Healthcare Commission. Healthcare Commission's Report on the review Healthcare Commission. Healthcare Commission's Report on the review
of NHS foundation trusts. 2005. www.healthcarecommission.org.uk of NHS foundation
(accessed 5 Jul 2005).

5 NHS foundation trusts. www.dh.gov.uk/PolicyAndGuidance/ NHS foundation trusts. www.dh.gov.uk/PolicyAndGuid
OrganisationPolicy/SecondaryCare/NHSFoundationTrust/fs/en (accessed 1 Jul 2005)

6 Klein R. The first wave of NHS foundation trusts. BMJ 2004;328:1332.

7 Lewis R. Governing foundation trusts-a new era for public accountability. London: King's Fund, 2005. www.kingsfund.org.uk/pdf/ governingfoundationtrusts.pdf (accessed 1 Jul 2005).

\title{
Epilepsy and driving
}

\section{Regulations in the European Union need harmonisation as well as greater flexibility}

$\mathrm{T}$ The lack of driving privileges is one of the major concerns of people with epilepsy. Seizures undoubtedly represent a potential source of accidents and injuries, and this justifies limitations on driving for people liable to epileptic seizures. Convincing evidence shows that in the absence of seizures (with or without treatment), the risk of accidents and injuries is clearly decreased and tends to be close to that of the general population. ${ }^{12}$

Unfortunately, the variability of published reports on risk has led to differing regulations for a driving licence among the members of the European Union and elsewhere in the world, ${ }^{3}$ with each jurisdiction developing and enforcing its own regulations on epilepsy and driving. The European Council Directive 91/439/EEC on driving licences reports, "a licence may be issued or renewed subject to an examination by a competent medical authority and to regular medical check-ups. The authority shall decide on the state of the epilepsy or other disturbances of consciousness, its clinical form and progress (no seizure in the last two years, for example), the treatment received and the results thereof." ${ }^{\prime 4}$ For commercial driving it states "driving licences shall not be issued for applicants or drivers suffering or liable to suffer from epileptic seizures or other sudden disturbances of the state of consciousness."

\section{Rules vary from state to state}

In the European Union, some member states, including the United Kingdom, require a one year period of freedom from seizures before granting or renewing a driving licence although most require a two year period. More variation exists about exceptions where people with active epilepsy may drive (for example, seizures during sleep, myoclonic 
seizures, simple partial seizures, and seizures only on awakening). In the United Kingdom, for example, the only exception to the rule is seizures occurring solely during sleep, with this pattern established for three years. But this pattern needs to be established for two years in Belgium and only one year in the Netherlands. The Republic of Ireland also requires the pattern to be established for one year, and the Netherlands allows people who have seizures during wakefulness that are not felt to impair driving ability (simple partial seizures) to drive. French legislation allows people with seizures only on awakening to drive. Regulations on commercial driving and supportive laboratory (electroencephalographic) criteria differ widely. In most countries of the European Union, the onus for reporting seizures to the driving authorities is on the individual.

\section{Patients' or authorities' perspectives?}

The issue of epilepsy and driving may have differing emphases depending on whose perspective is being considered. From a patient's perspective, the risk of seizure related accidents (rate ratio 1.8, 95\% confidence interval 1.7 to 2.0$)^{5}$ and the risk of serious accidents (odds ratio 1.4, 95\% confidence interval 1.0 to 1.8$)^{6}$ when epilepsy is active might be too high. Fewer than half of all epileptic seizures, however, occur in the context of established epilepsy (defined as repeated unprovoked seizures) ${ }^{7}$; the remainder consists of acute symptomatic seizures and single unprovoked seizures. Acute symptomatic seizures can be prevented by adequate control of the cause, whereas single unprovoked seizures have a smaller probability of relapse after the first 12 months. ${ }^{8}$ Even among people with active epilepsy, several epilepsy syndromes exist (for example, nocturnal tonic-clonic epilepsy or epilepsies with simple partial seizures), which may be compatible with non-commercial driving.

From the perspective of a health authority or insurance, the proportion of accidents attributable to active epileptic seizures is extremely low, ranging from $0.02 \%$ to $0.2 \%{ }^{9}{ }^{10}$ In this context, epilepsy compares favourably with alcohol abuse (up to $31 \%$ ) and young age (up to $24 \%$ ). ${ }^{10}$ Mandatory reporting of epilepsy by doctors to the driving authorities, where required, may have negative implications as it affects the relationship between doctor and patient or may expose a doctor who fails to report a patient's epilepsy to the risk of prosecution.

\section{Harmonise the rules}

An effort should be made by the driving authorities within the European Union to set common and more flexible rules considering epilepsy and seizures as a spectrum of clinical conditions, many of which are fully or partly compatible with non-commercial driving. Different periods of seizure freedom could be considered as a prerequisite for granting driving licences, depending on the type of epilepsy and seizure patterns. Acute symptomatic seizures should be considered separately, and may be compatible with non-commercial driving providing the underlying clinical condition is adequately identified and controlled. Likewise, patients with single unprovoked seizures should forego driving only for 12 months. In contrast, more strict rules should be set for commercial driving. Factors that determine risk of driving related accidents are the amount of time spent driving, number of previous accidents, and whether or not passengers are being transported. ${ }^{11}$ The driving authorities should consider carefully these variables when defining the length of the minimum seizure free period deemed necessary to grant or renew a driving licence.

All these issues have been dealt with in a review paper. ${ }^{12}$ They will also be discussed in a scientific report on epilepsy and driving in Europe, which is in preparation by the advisory board to the driving licence committee of the European Union, leading to the harmonisation of rules. For now, Europe wide legislation is still awaited.

A general practitioner seeing a person with newly diagnosed or suspected epilepsy who drives must encourage compliance with the national rules. A person with epilepsy who has driving privileges in one European country will not necessarily be entitled to drive in another country. Therefore, a detailed list of individual national rules on epilepsy and driving needs to be easily available, and doctors should alert their patients to the need to comply with these rules.

Ettore Beghi head

Laboratory of Neurological Disorders, Istituto “Mario Negri," Milan, Italy (beghi@marionegri.it)

\section{Josemir W Sander professor}

Department of Clinical and Experimental Epilepsy, University College London Institute of Neurology, London WC1N 3BG

Competing interests: EB has been elected as consultant for the assessment of the report of the second European working group on epilepsy and driving.

1 Van den Broek M, Beghi E, for the RESt-1 group. Accidents in patients with epilepsy: types, circumstances and complications: a European cohort study Epilepsia 2004:45:667-72.

2 Krauss GI, Krumholz A, Carter RC, Li G, Kaplan P. Risk factors for seizure-related motor vehicle crashes in patients with epilepsy. Neurology 1999;52:1324-9

3 Fisher RS, Parsonage M, Beaussart M, Bladin P, Masland R, Sonnen AE, et al. Epilepsy and driving: an international perspective. Join Commission on Drivers' Licensing of the International Bureau for Epilepsy and the International League Against Epilepsy. Epilepsia 1994:35:675-84.

4 Council Directive 91/439/EEC of 29 July 1991 on driving licences. Official Journal L 237, 24/08/1991 P. 0001-0024. http://europa.eu.int eur-lex/lex/LexUriServ/LexUriServ.do?uri = CELEX:31991L0439:EN: HTML (accessed 29 Apr 05).

5 Vaa T. Impairments, diseases, age and their relative risk of accident involvement: results from meta-analysis 2003. Report to the Institute of Transport Economics. www.toi.no/attach/a509491r891552/690 2003. pdf (accessed 10 May 2005).

6 Taylor J, Chadwick D, Johnson T. Risk of accidents in drivers with epilepsy. J Neurol Nurosurg Psychiatry 1996;60:621-7.

7 Hauser WA, Annegers JF, Kurland LT. Incidence of epilepsy and unprovoked seizures in Rochester, Minnesota: 1935-1984. Epilepsia 1993; 34:453-68.

8 Hauser WA, Rich SS, Lee JR, Annegers JF, Anderson VE. Risk of recurrent seizures after two unprovoked seizures. $N$ Engl J Med 1998:338:429-34.

9 Black AB, Lai NY. Epilepsy and driving in South Australia-an assessment of compulsory notification. Med Law 1997;16:253-67.

10 Sheth SG, Krauss G, Krumholz A, Li G. Mortality in epilepsy: driving fatalities vs other causes of death in patients with epilepsy. Neurology 2004; 63:1002-7.

11 Sonnen AE. Epilepsy and driving: a European view. Paswerk Bedrijven, Netherlands: International Bureau for Epilepsy, 1997:11-32.

12 Schmedding E. Epilepsy and driving in Belgium: proposals and justification. Acta Neurol Belg 2004;104:68-79. 